\title{
JUVENTUDE E CIDADANIA NA SULANCA E A POLÍTICA DO PROJOVEM
}

\section{YOUTH AND CITIZENSHIP IN THE SULANCA AND THE POLICY OF PROJOVEM}

\author{
Marcelo Alves P Eufrasio ${ }^{1}$
}

\section{RESUMO}

Esta pesquisa tem como principal objetivo investigar a política pública de escolarização e qualificação, particularmente quanto a implementação do Projovem Urbano no município de Caruaru-PE, uma região central do Agreste Pernambucano, onde se desenvolveu, desde a década de 1950, o Pólo de Confecções. Numa perspectiva sociológica foi estudada a realidade da inserção dos jovens no mundo do trabalho, sendo este um aspecto da garantia à cidadania social, sobretudo analisando os desafios, impasses e estratégias de construção de um protagonismo juvenil.

PALAVRAS-CHAVES: Política Educacional; Cidadania; Juventude.

\begin{abstract}
This research has as main objective to investigate the public politics of schooling and qualification, particularly regarding the implementation of Projovem Urbano in the municipality of Caruaru-PE, a central region of Agreste Pernambucano, where, since the 1950s, the Pólo de Confecções. From a sociological point of view, the reality of the insertion of young people in the world of work was studied, being an aspect of the guarantee to the social citizenship, especially analyzing the challenges, impasses and strategies of construction of a youthful protagonism.
\end{abstract}

KEYWORDS: Educational Policy; Citizenship; Youth.

\section{INTRODUÇÃO}

Este estudo pretende analisar a atuação da Política Nacional de Escolarização e Qualificação nas modalidades destinadas ao público juvenil, como ação governamental de garantia da cidadania social, particularmente no tocante aos direitos sociais, no tocante a atuação do Programa Nacional de Inclusão de Jovens - Projovem, tendo como recorte espacial o território conhecido historicamente como "Sulanca" e, atualmente, cada vez mais, como Pólo de Confecções do Agreste de Pernambuco. Trata-se de uma política nacional de escolarização e de qualificação profissional, destinada aos jovens de 18 a 29 anos que não concluíram o Ensino Fundamental. Vem se colocando num contexto histórico marcado por relações de trabalho de tipo precário e informal. Optamos por delimitar o presente estudo na atuação do

\footnotetext{
${ }^{1}$ Bacharel em Direito e Licenciado em História. Pós-Graduação em História da Filosofia, mestrado e doutorado em Ciências Sociais. Professor e pesquisador do Centro Universitário UNIFACISA. Departamentos de Direito e Engenharia Civil.

Revista Labor Fortaleza/CE, jul/dez 2018 n 20, Vol. 01, pp. 27-36 ISSN 1983-5000
} 
Projovem Urbano em Caruaru no Estado de Pernambuco, um dos mais importantes municípios da região compreendida pelo Pólo.

Em regiões como o Pólo, onde há combinação da predominância de dois fatores sociais de destaque, a informalidade no trabalho e a baixa escolarização e qualificação profissional, se acentuam cada vez mais precárias condições de inserção no mercado de trabalho, mesmo que com índices razoáveis de empregabilidade (trabalho precarizado) nos setores de confecção.

Desde 2005, quando da criação da Política Nacional de Juventude, por meio de Medida Provisória, essa política compreende três iniciativas principais: a constituição da Secretaria Nacional da Juventude, com o objetivo de monitorar e desenvolver as políticas de juventude; a implantação do Conselho Nacional de Juventude, com a finalidade de propor diretrizes governamentais, fazer estudos com a população jovem e assessorar a Secretaria Nacional de Juventude; e o Projovem, que se constitui enquanto um programa com caráter ao mesmo tempo emergencial e experimental (MACHADO; TENÓRIO, 2011).

O Projovem tem o objetivo estratégico, no âmbito da Política Nacional de Juventude, de proporcionar a integração entre ensino fundamental, qualificação profissional e ação comunitária. No tocante à modalidade Projovem Urbano, a responsável por sua execução e gestão é a Secretaria Geral da Presidência da República. O programa está voltado para jovens de 18 a 29 anos, que saibam ler e escrever, mas não tenham concluído o ensino fundamental.

O foco central da pesquisa foi entender essa política no caso do Pólo de Confecções do Agreste de Pernambuco. A questão que norteou a pesquisa foi como o Projovem Urbano atuou diante da informalidade, sendo como uma marca da configuração histórica e atual do Pólo, particularmente no município de Caruaru².

Para a realização desta pesquisa, os procedimentos metodológicos foram essencialmente qualitativos: levantamento bibliográfico, entrevistas semi-estruturadas, grupos focais, pesquisa documental e observação direta. No tocante às entrevistas, visou-se estabelecer um diálogo entre entrevistador e entrevistado, baseando-se nos principais temas e problemas que nascem do objeto de pesquisa.

\footnotetext{
${ }^{2} \mathrm{O}$ município de Caruaru foi escolhido objeto desta pesquisa em razão de sua importância como pólo produtivo e comercial na região do Agreste Pernambucano, mais, sobretudo porque a Política Pública do Projovem Urbano em nível nacional só foi implementada em municípios com mais de 200.000 habitantes, logo, no contexto do Pólo de Pernambuco só podia ser contemplado este município. 


\section{A PROBLEMÁtica dA INFORMALIDADE NO TRABALHO E A (DES) EMPREGABILIDADE DOS JOVENS}

A nova realidade das relações de trabalho no Brasil, baseada no novo padrão de acumulação flexível de capital e no neoliberalismo, passou a estruturar o setor produtivo e o mundo do trabalho a partir de uma lógica baseada na informalidade e na precarização, especialmente ao longo dos anos 1990. Neste contexto, as transformações no sistema produtivo acarretaram flexibilização e desregulamentação em diferentes setores econômicos. Tais mudanças implicaram, sobretudo nos anos de 1990, em um desmonte do aparelho político e do poder dos sindicatos, além da diminuição do poder de negociação dos trabalhadores no tocante aos mecanismos de proteção social.

Frente a esta realidade, os jovens se converteram nas principais vítimas destas transformações decorrentes da reestruturação produtiva e das políticas neoliberais. A situação dos jovens no mercado de trabalho no Brasil, em diferentes setores nos anos 1990/2000, esteve marcada por altas taxas de desemprego, refletindo de modo exacerbado as consequiências do processo econômico que teve início no mundo capitalista da década de 1970, sendo que, no caso brasileiro, este fenômeno impactou bastante a partir dos anos 1990 (POCHMANN, 2000). Enquanto nos anos de 1990, no Brasil, se intensificava o trabalho informal e precário e, conseqüentemente, o desemprego. Nos anos 2000, se assiste a certa recuperação nos índices de emprego, mesmo que entre os anos 2008/2009 com a crise econômica mundial, tendo este problema ganhado proporções maiores ao ponto de atingir os jovens que estavam procurando se inserir no mercado de trabalho.

No caso brasileiro, as mudanças na realidade econômica nacional entre os anos 1990/2000, principalmente no tocante ao impacto da precarização das formas de trabalho e da informalidade tem sido alvo de mudanças políticas, principalmente nos níveis de inserção escola-trabalho, que têm trazido sensíveis conseqüências para os jovens. O objetivo destas medidas seria, então, impactar na problemática de inserção dos jovens no mercado de trabalho, haja vista que a década de 1990 foi marcada pela intensa condição de vulnerabilidade social por parte daquela parcela da população.

Frente a isso, a partir de 2003, o Brasil vem experimentando a efetivação de medidas político-governamentais no sentido de promover um debate sobre o redimensionamento das mudanças ${ }^{3}$ que vinham ocorrendo nos setores político-econômicos

\footnotetext{
${ }^{3}$ Para o sociólogo Roberto Véras de Oliveira, as altas taxas de vulnerabilidade social que se refletiam nos altos índices de desemprego juvenil eram ocasionados nos anos 1990 pelas medidas de cunho neoliberal que pregavam a livre negociação e a flexibilização das relações de trabalho, das leis trabalhistas etc. Segundo esse posicionamento, a flexibilização deveria garantir o emprego, pois esta visava corrigir a inadequação entre oferta e demanda de emprego, logo estabelecendo um nivelamento entre os custos com o trabalho. Assim, a informalidade esteve Revista Labor Fortaleza/CE, jul/dez 2018 n² 20, Vol. 01, pp. 27-36 ISSN 1983-5000
} 
nacionais desde as medidas reformistas (neoliberais) dos governos Fernando Collor e Fernando Henrique Cardoso. Essas mudanças, ocorridas nas estratégias políticas recentes, ocasionaram alterações positivas no mercado de trabalho, como a elevação nas taxas de emprego, o aumento nos índices de formalização do emprego, nos níveis de salários entre outros. (KREIN, 2005).

A problemática atual que persiste diz respeito às condições de trabalho informal e ao trabalho precário, sobretudo em decorrência da transição para o governo provisório de Michel Temer que em alguma medida tenha gerado instabilidade frente às políticas de governo.

O que se pode afirmar é que se reproduzem as condições precárias, ao mesmo tempo em que vem ocorrendo melhoras nos indicadores sociais, justificados pelas ações públicas no sentido do fomento a um desenvolvimento econômico e social com alguma distribuição de renda. A condição precária no trabalho continua atingindo prioritariamente jovens. Afirma Santos (2011) que, para os jovens na faixa etária de 15 a 24 anos, o grau de dificuldade de inserção no mercado de trabalho aumenta, pois, em muitos casos, essa faixa de idade é considerada despreparada, desqualificada e propensa apenas ao desenvolvimento de atividades de menor especialidade e importância.

Os desafios que perpassam a formação do jovem trabalhador estão intimamente relacionados a obtenção da escolarização necessária, bem como a comprovação da experiência exigida. Segundo dados de 2010, da Síntese de Indicadores Sociais levantados pelo Instituto Brasileiro de Geografia e Estatística - IBGE, entre os jovens de 18 a 24 anos de idade no Brasil, mais de 1,2 milhão não tinham nenhuma atividade produtiva. Essa enorme inatividade juvenil atingia 5,37\% dos 23.242.000 de jovens desta faixa etária residentes no país, ou seja, em boa parte deles havia desemprego.

A atual condição juvenil é perpassada por desafios maiores, como a problemática da informalidade no trabalho, que afeta diretamente a (des) empregabilidade dos jovens. Essas condições são agravadas quando se constata a carência de proteção social, a fragilidade das ações governamentais e a ausência de interesse pela inclusão social.

Para Richard Sennett (2006), estes elementos repercutem negativamente no cotidiano dos trabalhadores, que acabam vivenciando situações de insegurança e instabilidade, como, por exemplo, baixa remuneração, instabilidade no trabalho, pouca ou nenhuma qualificação e escolarização, tornando-os vulneráveis diante do mercado de trabalho cada vez mais intenso e exigente.

associada ao desemprego, aos processos de heterogeneização das formas e vínculos de trabalho, bem como à terceirização, à flexibilização e à precarização das relações de trabalho (OLIVEIRA, 2011).

Revista Labor Fortaleza/CE, jul/dez 2018 nº 20, Vol. 01, pp. 27-36 ISSN 1983-5000 
Como impacto dessa realidade, surgem as alternativas ocupacionais destinadas ao público juvenil, que se encontra a mercê das exigências do mercado de trabalho e condicionados à vulnerabilidade social. Estes se constituem enquanto "exército industrial de reserva", presos às piores condições de empregabilidade e sujeitos às diferentes formas de precarização das formas de trabalho. A medida encontrada como alternativa para a subsunção ao capitalismo flexível, por sua vez, seria agarrar-se às piores condições de trabalho, conforme se enuncia a seguir:

\begin{abstract}
As alternativas ocupacionais mais comuns entre os jovens são, grosso modo, bastante precárias, ou seja, trata-se de ocupações que não exigem níveis elevados de qualificação, mas que vêm sendo preenchidas por pessoas com alguma escolaridade formal. Isso acontece em virtude do crescente movimento da escolaridade, sobretudo daquela referente à faixa etária dos 18 aos 24 anos. O numero reduzido de ocupações absorvedoras de trabalhadores jovens faz com que se verifique uma intensificação da concorrência entre pessoas, fazendo até mesmo que cresçam formas discriminadoras nesse segmento do mercado de trabalho (MENEZES; CARRERA-FERNANDEZ, 2011, p. 73).
\end{abstract}

A realidade em que se encontra a problemática de inserção ocupacional dos jovens remonta a uma série de fatores intimamente interligados, que condicionam este grupo etário, particularmente entre os 18 e os 24 anos, a condições precárias de trabalho.

Neste cenário, há a necessidade de priorizar medidas de enfrentamento dos problemas do emprego e da escolarização, que enfatizam a questão da educação, uma vez que a situação mais premente é a dedicação dos jovens aos estudos, mesmo que seja necessário enfatizar a conciliação entre estudo e trabalho.

\title{
CONJUNTURA DOS JOVENS NA SULANCA E POLÍTICA DE ESCOLARIZAÇÃO E QUALIFICAÇÃO NO DIREITO À CIDADANIA
}

A realidade do Pólo da Moda do Agreste de Pernambuco contrasta com alguns aspectos sociais e econômicos que envolvem a empregabilidade e o faturamento no setor de confecções. Economicamente, aquela região é responsável por, aproximadamente, $75 \%$ da atividade industrial relacionada ao segmento de vestuário do Estado, atividades produtivas e comerciais voltadas ao setor de confecções. Mas, que têm se reproduzido as formas de precarização das relações de trabalho, particularmente por meio da informalidade no trabalho.

Segundo estudos realizados no Pólo ${ }^{4}$, apesar do desenvolvimento econômico acentuado na região, este crescimento não foi capaz de aumentar o número de empregos

\footnotetext{
${ }^{4}$ Desde a primeira década dos anos 2000, que são registrados estudos sobre a realidade do Pólo de Confecções do Agreste Pernambucano, entre eles, se destacam os que estamos trabalhando nesta pesquisa a partir dos dados e estudos realizados, sendo eles, as duas pesquisas do SEBRAE (2003; 2013), além das pesquisas acadêmicas realizadas pelo Grupo de Pesquisa Trabalho, Desenvolvimento e Políticas Públicas TDEPP-UFCG em nível de mestrado e doutorado pelos pesquisadores da área de Sociologia do Trabalho.

Revista Labor Fortaleza/CE, jul/dez 2018 n² 20, Vol. 01, pp. 27-36 ISSN 1983-5000
} 
formais. O desenvolvimento local resulta em baixa arrecadação tributária, além de comprometer o investimento público para o desenvolvimento das cidades que compõem o Pólo, inclusive quanto a implementação de polícias sociais. Segundo Ferreira (2011), contatou-se, a partir de entrevistas com feirantes dos municípios de Caruaru, Toritama e Santa Cruz do Capibaribe, que a maioria dos envolvidos no setor de confecções, particularmente os feirantes, não tem interesse em sair da informalidade. Para alguns dos feirantes, é mais vantajoso permanecer na informalidade, evitando pagar impostos, com o objetivo de aumentar seus lucros, mesmo que permaneçam em situação irregular perante o fisco e estejam fora dos mecanismos de proteção social oferecidos pelo Estado. Esse problema, todavia, afeta também outros aspectos da vida social. No tocante à questão escolar, essa realidade atinge negativamente pelo menos dois aspectos: primeiro, a rejeição de parte dos trabalhadores informais pela participação nas ações públicas, desde o pouco interesse na contribuição tributária até a pouca inserção nas políticas educacionais, este último fator expresso, por exemplo, no problema da evasão escolar. Um segundo aspecto, concomitantemente à precarização das formas de trabalho, está também na precarização das políticas públicas, devido à ausência de participação de setores da população e a baixa arrecadação para investimentos.

Diante destas problemáticas, desde 2005, o Governo Federal tem investido em políticas de escolarização para jovens no sentido de melhor adequá-los ao mercado de trabalho. O Projovem Urbano, política pública vinculada à Secretaria Geral da Presidência da República, é responsável pela garantia de educação aos jovens. O programa está voltado para jovens de 18 a 29 anos, que saibam ler e escrever, mas não concluíram o ensino fundamental. É um componente do Sistema Único de Assistência Social - SUAS, implementado pela atuação conjunta do Governo Federal, Estados, Municípios e Distrito Federal, além de integrado pela Política Nacional de Assistência Social (PNAS/2004) ${ }^{5}$.

O Projovem articula, portanto, um conjunto de ações de proteção social, além de buscar desenvolver seguranças sociais de acolhida, convívio familiar e comunitário. Destinase, pois, aos jovens de famílias em condições de vulnerabilidade social.

As atividades desenvolvidas pelo Projovem Urbano em Pernambuco, mais precisamente no território do Pólo de Confecções, se articulam com as atividades socioeconômicas para o acesso a qualificação, inserção e promoção de emprego e geração de renda dos jovens, principalmente com a criação de cursos profissionalizantes ligados ao setor de design e produção de vestuário. Há interesse por parte dos empreendedores em contratar

${ }^{5}$ Sobre esta idéia protetiva, Sposito (2007, p. 17) entende que "estar protegido significa ter forças próprias ou de terceiros, que impeçam alguma agressão/precarização/privação que venha a ocorrer, deteriorando uma dada condição".

Revista Labor Fortaleza/CE, jul/dez 2018 n² 20, Vol. 01, pp. 27-36 ISSN 1983-5000 
profissionais da moda, como estilistas e designers, mas, devido à escassez destes profissionais na região e do custo elevado da mão de obra especializada em moda, poucas empresas declaram contratá-los. Apenas “7\% das empresas recorrem a estilistas ou designers contratados para produzir suas criações, indicando o desenvolvimento (ainda incipiente, na verdade) de um mercado para esses profissionais". Os demais utilizam 22\% de cópias de peças, $4 \%$ fazem sua própria criação e 24\% utilizam livros, revistas técnicas e/ou internet (SEBRAE, 2013, p. 72).

Segundo dados do Atlas de Desenvolvimento Humano (2013), no IDH de Pernambuco a educação tem média de 0,621 , um pouco acima dos dados sobre longevidade e renda. Os dados apontam um nível educacional muito baixo da população jovem e adulta, sendo a taxa de analfabetismo de 53,17\% e a média de anos de estudos de 2,42\%. O índice de escolarização na faixa etária de 15 a 24 anos é de 22,7\%. Somado a estes problemas estão os altos índices de evasão escolar e repetência, principalmente em localidades rurais e em regiões pernambucanas onde as crianças e jovens exercem atividades produtivas ainda muito cedo (BRASIL, 2011).

A partir desta realidade, delineia-se nova perspectiva sobre a juventude, em que perde força a conotação problemática do jovem e ganha relevo um enfoque completamente inovador: a juventude torna-se ator estratégico do desenvolvimento. Medidas decorrentes deste novo enfoque, no geral, reatualizam a visão preparatória da juventude, exigindo, por um lado, investimentos massivos na área de educação em prol do acúmulo de "capital humano" pelos jovens; por outro, exigindo também a adoção do corte geracional nos vários campos da atuação pública - saúde, qualificação profissional, uso do tempo livre etc. - e o incentivo à participação política juvenil, com recurso à noção de protagonismo jovem.

\section{CONSIDERAÇÕES FINAIS}

Parte significativa da população juvenil permanece em situação de vulnerabilidade social. Essa constatação é evidenciada pelas estatísticas dos últimos anos em torno de temas como violência, desemprego e baixa escolaridade. Esta situação coloca os jovens frente a grandes desafios. Devem em primeiro lugar ser reconhecidos como sujeitos de direitos. Constituem um segmento populacional estratégico no processo de desenvolvimento do país, que deve ser incluído no âmbito das políticas públicas.

No contexto do Pólo, a política de escolarização e qualificação, particularmente o Projovem Urbano, não obstante as oportunidades criadas, os esforços muitas vezes empreendidos por gestores, professores e alunos, não têm conseguido atuar de modo mais incisivo na superação de um padrão de relações de trabalho que é caracteristicamente informal 
e precário. Há, cada vez mais evidenciada, carência de mão de obra especializada e qualificada em muitos setores ligados ao Pólo, de modo a torná-lo mais capaz de enfrentar a concorrência externa e oferecer maior variedade de produtos e modelos.

Em grande medida, parte dos jovens que estão na sulanca pretendem, com o retorno à escola, se reinserir no Pólo por meio da incorporação de capital cultural ${ }^{6}$. Isso ocorre em vista da grande ausência de educação formal e de uma diversidade de valores culturais acumulados nas famílias dos jovens. Sob tais condições, a juventude da sulanca não pode usufruir das mesmas condições educacionais das classes sociais mais favorecidas.

Desse modo, o sistema escolar privilegia os modos de avaliação a partir de critérios de distinção social. Os estudantes de classes sociais menos favorecidas, a exemplo dos jovens descritos aqui, são vistos pelas políticas educacionais tradicionais como atrasados, sem aptidões e desprovidos de capacidades e habilidades. Assim, são rejeitados ou excluídos do processo produtivo legalizado ou oficialmente reconhecido pelo Estado, que se reproduz mediante os mecanismos de seleção de empregos formais, como, por exemplo, "ter experiência na vaga de costureira" ou "possuir o ensino médio completo".

Sendo configurada tal relação como violência simbólica nos termos de Bourdieu (1970), este processo social tem justificado a inserção dos jovens do Pólo na informalidade do mundo do trabalho, apesar da existência de uma política educacional que defende a escolarização, qualificação e cidadania dos jovens. Como não há garantias de emprego formal e nem de emancipação social, os jovens da região preferem permanecer reproduzindo as relações sociais construídas espontaneamente, voluntariamente e informalmente, sem a participação direta das estratégias governamentais, reproduzindo as mesmas condições históricas que formaram o Pólo de Confecções do Agreste de Pernambuco.

As políticas de escolarização e qualificação profissional têm contribuído para a reprodução, em grande medida, das estratégias econômicas prevalecentes na região, adaptando elementos característicos da lógica do capitalismo e das estratégias de sobrevivências, a exemplo do que ocorre no território do Pólo. Neste sentido, a garantia à cidadania preconizada como afirmação do acesso aos direitos básicos, previstos na Constituição da República no artigo $7^{\circ}$, como, por exemplo, a educação, também reproduzem o contexto e desafios acentuados no pólo, sobretudo sua fragilidade perante a lógica do capital.

\footnotetext{
${ }^{6}$ Defende Bourdieu e Passeron (1970; 2007) que o capital cultural é identificado como uma forma de expressar os conhecimentos e habilidades adquiridos dentro da família, da escola ou dos diferentes espaços e experiências sociais. Nesta perspectiva de abordagem teórica, esta categoria sociológica foi pensada como uma hipótese indispensável para compreender as desigualdades de desempenho escolar das crianças originárias de diferentes classes sociais.

Revista Labor Fortaleza/CE, jul/dez 2018 n² 20, Vol. 01, pp. 27-36 ISSN 1983-5000
} 


\section{REFERÊNCIAS BIBLIOGRÁFICAS}

AQUINO, Cássio Adriano Braz de. O processo de precarização laboral e a produção subjetiva: um olhar desde a Psicologia Social. In. Jan/Jun, 2009. p. 169-178.

O público e o privado. $n^{\circ} 11$,

Atlas de Desenvolvimento Humano (2013). Índice de Desenvolvimento Humano Municipal (IDHM). Disponível em: http://www.atlasbrasil.org.br/2013/. Acesso em: ago. 2013. BOURDIEU, Pierre; PASSERON, Jean-Claude. A reprodução: elementos para uma teoria do sistema de ensino. Lisboa: Ed. Vega, 1970.

BOURDIEU, Pierre. O poder simbólico. Rio de Janeiro: Bertrand Brasil, 2007.

BRASIL. Política Nacional de Assistência Social - PNAS (2004). Norma Operacional Básica. Ministério do Desenvolvimento Social e Combate à Fome. Secretaria Nacional de Assistência Social. Brasília, Nov. 2005.

BRASIL. Pró-Jovem Urbano. Governo Federal. Disponível em: http://www.projovemurbano.gov.br/site/index.php. Acesso em: ago. 2011.

CAMPELLO, Cristina Maria Teixeira; BAPTISTA, Creomar; MENEZES, Antonio Wilson Ferreira. Construção de uma política social para os jovens de Salvador: estratégias de combate à violência e pela inclusão social. Salvador: SEPLANTEC/SPE, 2002.

FERREIRA, Monaliza de Oliveira et al.. Estimativa de demanda pela formalização da economia informal no Agreste Pernambucano - uma aplicação do método de valorização contingente. Anais do I Circuito de Debates Acadêmicos - CODE 2011. IPEA, 2011.

IBGE. Instituto Brasileiro de Geografia e Estatística. (2010). Disponível em: http://www.sidra.ibge.gov.br/bda/territorio/infounit.asp?codunit $=1928 \&$ codunitibge $=2604106$ $\&$ nomeunit $=C$ aruaru $+\% 2 \mathrm{D}+\mathrm{PE} \& \mathrm{n}=6 \&$ nomenivel $=$ Munic $\% E D p i o \& \mathrm{z}=\mathrm{t} \& \mathrm{o}=4$. Acesso em: ago. 2012.

KREIN, José Dari; GONÇALVES, José Ricardo Barbosa . Mudanças Tecnológicas e seus Impactos nas Relações de Trabalho e no Sindicalismo do Setor Terciário. In. DIEESE/CESIT. (Org.). O Trabalho no Setor Terciário: Emprego e Desenvolvimento Tecnológico. São Paulo: DIEESE, 2005. p. 193-218.

LIMA, Alexandre Santos. Empreendendo a Sulanca: O SEBRAE e o Pólo de Confecções do Agreste de Pernambuco. Campina Grande, 2011. (Dissertação de Mestrado). UFCG - CH. Programa de Pós-Graduação em Ciências Sociais, 2011.

MACHADO, Cristiane Brito; TENÓRIO, Robinson Moreira. Juventude e participação: o caso da ação comunitária do Pró-Jovem. Bahia Análise \& Dados. Salvador: SEI, v. 11, n.1, p. 6981 , julho/2011.

MENEZES, Wilson F.; CARREIRA-FERNANDEZ, José. O estado atual do mercado de trabalho de trabalho juvenil na cidade de Salvador. Bahia Análise \& Dados. Salvador: SEI, v. 11, n.1, p. 69-81, julho/2011. 
OLIVEIRA, Roberto Véras de. O Pólo de Confecções do Agreste de Pernambuco: ensaiando uma perspectiva de abordagem. In. ARAÚJO, Ângela Maria Carneiro; OLIVEIRA, Roberto Véras de. Formas de trabalho no capitalismo atual: condição precária e possibilidades de reinvenção. São Paulo-SP: Annablume, 2011.

POCHMMAN, Marcio. A inserção ocupacional e o emprego dos jovens. São Paulo: Associação Brasileira de Estudos do Trabalho - ABET, 1998.

POCHMANN, Marcio. O emprego e o excedente de mão de obra brasileiro. In . $\mathbf{O}$ emprego na globalização: a nova divisão internacional do trabalho e os caminhos que o Brasil escolheu. São Paulo: Boitempo, 2000. p. 95-122.

SANTOS, Carlos Eduardo Ribeiro; SANTOS, Magila Souza. Os jovens e o mercado de trabalho nas regiões brasileiras: realidade, dificuldades e possibilidades no contexto recente. In. Bahia Análise \& Dados. Salvador: Superintendência de Estudos Econômicos e Sociais da Bahia, 2011. p. 25-42.

SEBRAE. Estudo Econômico do APL do Pólo de Confecções do Agreste Pernambucano. Relatório final. Serviço de Apoio às Micro e Pequenas Empresas do Estado de Pernambuco. Sebrae/Pernambuco. Recife: maio de 2013.

SEBRAE. Estudo de Caracterização Econômica do Pólo de Confecções do Agreste Pernambucano. Relatório Final coordenado por Maria Cristina Raposo e Gustavo Maia Gomes. Recife: Fundação de Apoio ao Desenvolvimento da Universidade Federal de Pernambuco - UFPE, 2003.

SENNETT, Richard. A cultura do novo capitalismo. Rio de Janeiro: Record, 2006.

SPOSITO, Marília. Trajetória na construção de políticas públicas de juventude no Brasil. In. FREITAS, Maria V. et. al. (Org.). Políticas públicas: juventude em pauta. São Paulo: CORTEZ, 2007. p. 13-51. 